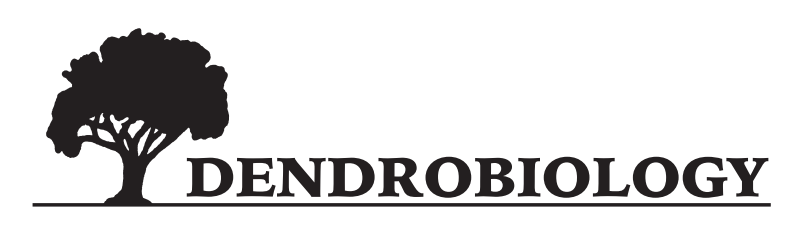

2018, vol. 79, 77-89

http://dx.doi.org/10.12657/denbio.079.007

\author{
Constantin Nechita, Francisca Chiriloaei*
}

\title{
Interpreting the effect of regional climate fluctuations on Quercus robur L. trees under a temperate continental climate (southern Romania)
}

Received: 6 July 2017; Accepted: 27 November 2017

\begin{abstract}
To determine oak tree sensitivity to climate fluctuations as a precipitation predictor, we eliminated monthly climate data and computed the growth-precipitation correlation using mean daily values calculated in time intervals. Precipitation from March through May is the primary limiting factor in intra-annual tree-ring growth for Quercus robur L. in southern Romania. Bootstrap correlations between the residual series and monthly average precipitation showed a positive dependence $(r=0.4)$. Using CLIMTREG software and daily climate data, we obtained correlation values of (0.6) and a better understanding of on-going tree radial growth. We found that the oak growth process is active during two distinct periods in the study area, December $22^{\text {th }}-$ February $10^{\text {th }}$ (earlywood) and March 04 ${ }^{\text {th }}$-June $13^{\text {th }}$ (latewood). For the studied oak tree population, the correlation with climate was positive with respect to precipitation and negative with respect to temperature. This indicates that annual tree-ring formation was influenced by the precipitation regime and frequency and by the degree of drought. These results also indicate that different behaviours occur among the examined earlywood and latewood under the same climatic conditions, which were then analysed.
\end{abstract}

Keywords: intra-annual growth, dendroclimatology, growth-climate relationship, Romania

Addresses: C. Nechita, National Institute for Research and Development in Forestry "Marin Drăcea" INCDS, Calea Bucovinei 73 bis, 725100, Câmpulung Moldovenesc, Romania

C. Nechita, F. Chiriloaei, Department of Geography, Stefan cel Mare University of Suceava, Universitatii

13, 720229, Suceava, Romania, e-mail: francisca@usm.ro

\section{Introduction}

Oak dendrochronology in Europe has made significant contributions to the understanding of climate variability across various time scales, from centuries to millennia (Friedrichs et al., 2008; Cooper et al., 2013; Dobrovolný et al., 2015). Oak trees are often studied in dendroclimatology due to their high sensitivity to local and regional climatic conditions. This species is mainly affected by drought stress conditions (Lebourgeois et al., 2004; Čufar et al., 2008a; Čufar et al., 2008b; Koláŕ et al., 2012), but it can also be negatively affected by the influence of temperature (García-Suárez et al., 2009). By analysing tree-ring growth at intra-annual levels, oaks offer valuable information, including information on environmental 
factors related to climate fluctuations in the year preceding ring formation (Garcia-González \& Eckstein, 2003).

Oak dendrochronology is a growing field, especially in Europe (Čufar et al., 2008b), such that Haneca et al. (2009) stated that oak is an excellent species for growth ring research. Analyses of oaks have been undertaken in large tree communities, but the studies have also provided results at the individual tree level (van der Maaten-Theunissen \& Bouriaud, 2012).

Investigations of climate signals preserved within tree-rings have involved separating radial growth into intra-annual components, including at the intracellular level (Fonti et al., 2010). The classical statistical models in these analyses used mean monthly climate data correlated with residual indices of dendrochronological series. Several studies have eliminated the monthly barrier that results from using mean monthly climate data (Pritzkow et al., 2016) by analysing the relationship between dendrochronological residual series and mean daily climate data over cumulative periods.

A recent study noted that oak trees from Central and Eastern Europe include characteristics related to oak trees of the study area (Ważny et al., 2014). Although there are several studies for Central and Eastern Europe, (Kern et al., 2013; Čufar et al., 2014; Stajić et al., 2015), the dendroclimatological studies for oak species published that include Romania (Nechita, 2013; Nechita et al., 2017) do not include southern Romania (Vlasiei Plain), which has specific climate-related features. Our study area is located at the eastern border of the continental climate regime that experiences significant impacts from drought. Additionally, the Mediterranean climate is observed in the second half of the growing season when the largest amount of precipitation is reported, which has a direct impact on tree growth. Analysing the influence of these regional climate fluctuations on oak trees is important, especially because the effect of drought is significant (Gentilesca et al., 2017).

For this study, we used growth-climate analysis based on monthly and daily data to investigate (i) if drought is the main driver of tree growth in the study area and (ii) what different types of environmental information can be determined from tree-ring width, specifically earlywood and latewood widths. The importance of this study is demonstrated by the fact that oak trees from the studied region can be used for palaeoclimate reconstructions.

\section{Materials and methods}

The sampled trees originated from a part of the Vlăsia Woods (the old growth forest that covered most of the Romanian Plain until the Late Middle Ages) that still exists in the study area, 46 $36^{\prime} 31^{\prime \prime}$, $25^{\circ} 26^{\prime} 56^{\prime \prime}$ (Fig. 1). The tree species in this area include Quercus robur L, Quercus cerris L and Fraxinus excelsior L. The age of trees was estimated at 150-170 years. The substrate is composed of soft Quaternary rocks (sands, clays) over which a well-structured chernozemic soil developed. The size of the study area was 429 hectares (Văcăreasca Body).

After the $17^{\text {th }}$ century, the pre-existing forest was harvested to allow for agricultural crops. The forest that now exists is a managed forest, and the trees originated from natural regeneration, rarely plantations (after the mid- $20^{\text {th }}$ century). The distribution of the trees by diameter class indicates an uneven-aged stand, with diameters that are as large as $68 \mathrm{~cm}$.

\section{Tree-ring chronology construction}

Increment cores from 60 oaks were collected, fixed on wooden boards, air-dried and sanded. Earlywood width (EW), latewood width (LW) and ring width
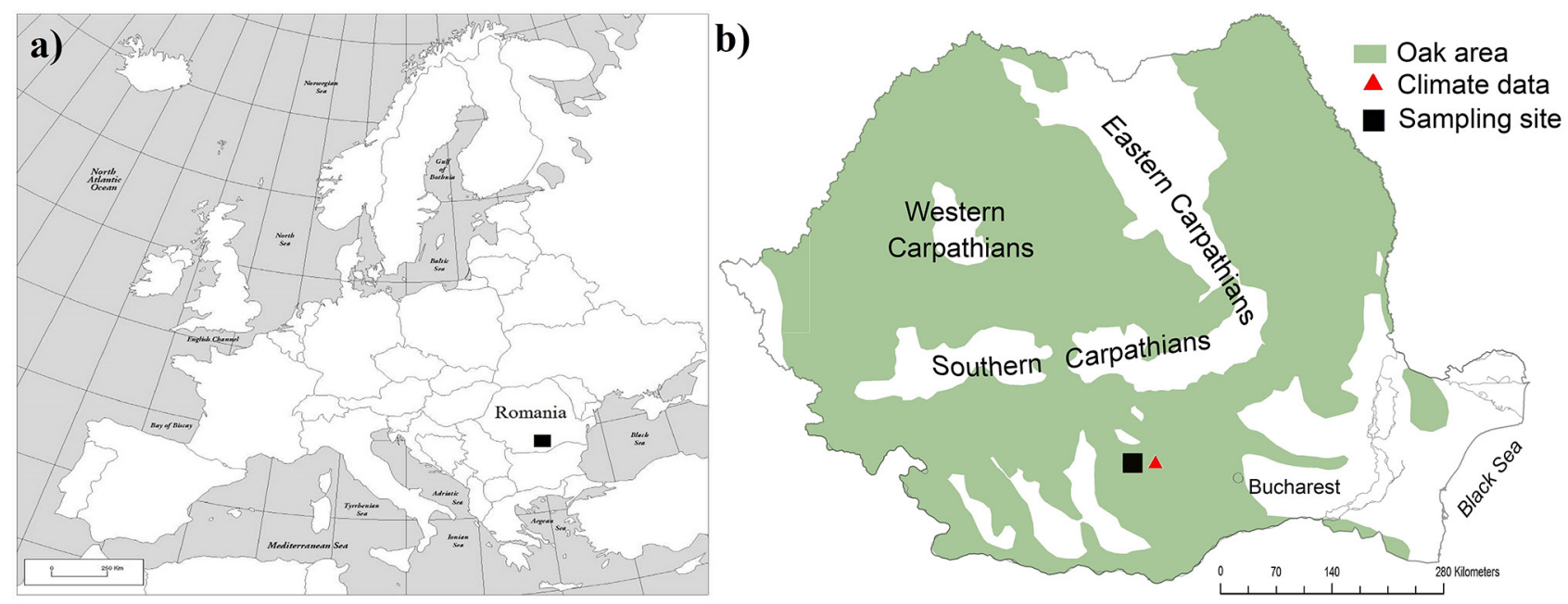

Fig. 1. Location of the study area (a) in south-eastern Europe and (b) in the southern part of Romania 
(RW) were measured to a precision of $1 / 1000$ using a LINTAB measuring device (RINNTECH) and the TSAPWin program (Rinn, 1996). The samples were processed according to the principles of dendrochronology (Fritts, 1976). The time series were cross-dated visually and statistically, using the TSAPWin and COFECHA programs (Holmes, 1983). The age and non-climatic trends were removed using ARSTAN (Cook \& Holmes, 1986). We applied a cubic smoothing spline with $50 \%$ frequency response cut-offs of 67 years length to standardize the growth series. The statistical quality of each single chronology was evaluated using classical dendrochronological parameters (Briffa \& Jones, 1990), such as the mean correlation between trees (Rbar), expressed population signal (EPS), percentage of variance in the first eigenvector (VCVP in \%) and signal-to-noise ratio (SNR). The Rbar is a statistic independent of sample size and represents the mean correlation coefficient for all possible pairs of tree-ring series from individual trees over a common time interval. The EPS measures chronology and is a function of the Rbar and series replication (Briffa \& Jones, 1990). EPS value of 0.85 was used as a threshold for the reliability of chronologies (Wigley et al., 1984; Cook et al., 1990; Buras, 2017). The signal-to-noise ratio expresses the strength of the observed common signal among trees. Three chronologies were built for TRW, EW and LW.

\section{Present climatic conditions}

Climate data (temperature and precipitation) for the study were obtained from the national climate grid, ROCADA (Dumitrescu \& Birsan, 2015). The grid contains daily records of nine meteorological variables, covering 1961-2013 at a spatial resolution of $10 \times 10 \mathrm{~km}$. We used the CRU TS3.24 dataset (Harris et al., 2014) to analyse the climate regime and identify the pointer years.

We selected the standardized precipitation evaporation index (SPEI3) for analysing tree-ring formation dependence to drought since its value has a normal distribution, and it can be used as a proxy for monitoring drought and excessive rain intervals. The values of the index are normalized; therefore, the two periods (drought and excessive rain) will be similarly represented. The SPEI3 index values for 1902-2008 were taken from the CRU database (Harris et al., 2014). Drought intensity is defined based on the SPEI3 index values for extreme drought events, which are values lower than -2.00 (McKee et al., 1993). The analysed data shows intervals with extreme rain events, which are defined as two standard deviation thresholds, (1912, 1940, 1957, 1963, $1966,1972,1975,1984,1991)$ and intervals with extreme drought $(1907,1932,1934,1945,1947,1952$, 1968, 1990, 2000, 2002, 2003, 2007).
The study area is characterized by a temperate continental climate, where summers are hot and winters are cold and snowy. The multi-annual mean air temperature reaches $8-11^{\circ} \mathrm{C}$, based on the calculations for the interval 1961-2013. The mean June temperature varies from $18-23^{\circ} \mathrm{C}$, while the mean January temperature ranges between -3 and $-5^{\circ} \mathrm{C}$ in the east and between -1 and $-3^{\circ} \mathrm{C}$ in the west. The multi-annual mean precipitation values are below $500 \mathrm{~mm}$ in the east and approximately $500-700 \mathrm{~mm}$ in the western area of the study area.

Maximum mean temperatures are recorded in July and August and reach approximately $27^{\circ} \mathrm{C}$. Negative temperatures were recorded in March in 1969, 1987 and 1996. Average daily precipitation values are at a maximum in June $(2.19 \mathrm{~mm} /$ day $)$ and a minimum in March (1.08 mm/day). In relation to temperature, in January, precipitation is highest and falls mainly as snow.

Snowmelt occurs gradually and has a direct relationship with water absorption by plant roots. The annual precipitation regimes within the study area experienced changes during the observation time intervals. Between 1950 and 1989, most precipitation fell in May and June. From 1989 to the present, precipitation decreased in the first half of the growing season and increased in the second half. A similar phenomenon has also been observed in Central Europe over the last twenty years (Trnka et al., 2015).

\section{Climate-growth analysis}

Most of the analysis used climate data from 1961-2013, based on time series from the climate data grid. To assess relationships between climatic variables and oak growth indices, we used Pearson correlation coefficients, response functions, the stability of the climate-growth relationship and pointer years. The correlation analysis was carried out using DENDROCLIM software (Biondi \& Waikul, 2004) from the previous August to the current August, for a period of 13 months. The temporal stability of the correlation was analysed on 24-year forward evolving intervals, at a step of one year.

Pointer years indicate the influence of climate upon tree-ring formation, and the intensity of the climatic event is determined based on the number of trees that reflect that extreme climate event in their tree-ring formation. Pointer years were analysed according to Becker et al. (1994), in which $100 \%$ of the series show the same trend of radial growth. The extreme years were determined by applying the statistical analysis of the normalized values within a moving window (Cropper, 1979). The event-years were set after establishing the significance limit at $1.75 \mathrm{SD}$ (standard deviation) and the frequency to values higher than $75 \%$ of the total number of series. 
The correlation between precipitation and the series of indices was computed in the CLIMTREG program (Beck et al., 2013). The program uses daily climate data at intervals of 21 to 121 days, starting from August 1st of the preceding year to August 31st of the current year.

\section{Results}

\section{The statistical parameters of the dendrochronological series}

Mean LW exceeds the mean EW width of oak from south Romania. The time span of the residual chronology was 1837-2009 (172 years). The mean radial growth of TRW is $2.04 \mathrm{~mm}$ /year, and it is separated in two distinct values for LW and EW, $1.18 \mathrm{~mm} /$ year and $0.86 \mathrm{~mm} /$ year, respectively. Considering the moving window analysis (Fig. 2), the EPS values never decrease to below 0.89 for EW and never below 0.97 for LW and RW. The Rbar value fluctuates above and below the 0.30 level for EW, while it exceeds this level for LW and the 0.53 level for RW, for the entire record (Fig. 2).

The correlation between the individual series and the mean series indicates a high homogeneity of ecological conditions in the study area (slope, soil type, and solar radiation, among others). The first-degree autocorrelation was calculated by using the Durbin-Watson statistics; the Kruskal-Wallis variance analysis and the Tukey test was applied to the growth series to yield minimum values of the autocorrelation index (-0.09). The autocorrelation index related to TRW (0.55) represents the average of the values calculated for EW and LW, which were 0.60 and 0.48 , respectively (Table 1 ).

Testing the correlation between the individual series and the mean, there is a common correlation value for LW and TRW (0.74); in contrast, the correlation value of EW was 0.47 . From TRW, the proportion of LW is $57.84 \%$, while EW represents the difference of $42.16 \%$. Nevertheless, the correlation between TRW and LW is 0.94, while lower coefficient was computed for TRW and EW (0.42) (Fig. 2).

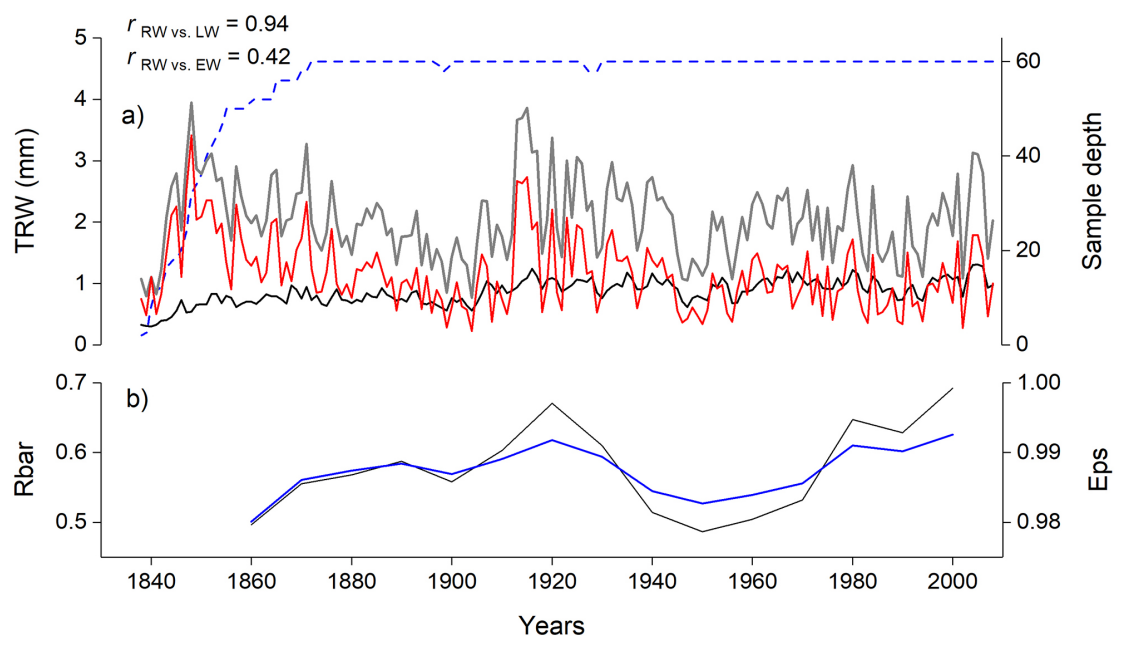

Fig. 2. Raw tree-ring chronologies for trees in the studied site: a) grey (TRW), red (LW), black (EW), blue (sample depth) and b) black (Rbar), blue (Eps) for TRW chronology

Table 1. The statistical parameters of the dendrochronological series

\begin{tabular}{|c|c|c|c|c|c|c|}
\hline \multirow{2}{*}{$\begin{array}{l}\text { Statistical } \\
\text { parameters }\end{array}$} & \multicolumn{3}{|c|}{ Growth series (RAW) } & \multicolumn{3}{|c|}{ Residual growth indices series (RES) } \\
\hline & RW & EW & LW & RW & EW & LW \\
\hline IC & 0.74 & 0.47 & 0.74 & - & - & - \\
\hline MS & 0.30 & 0.21 & 0.51 & 0.28 & 0.15 & 0.45 \\
\hline SD & 0.90 & 0.29 & 0.77 & 0.26 & 0.17 & 0.40 \\
\hline SNR & 14.46 & 5.08 & 15.21 & 15.74 & 4.32 & 15.79 \\
\hline VPCP $(\%)$ & 57.66 & 33.75 & 58.68 & 59.22 & 30.64 & 59.21 \\
\hline Rbar & 0.45 & 0.32 & 0.50 & 0.57 & 0.26 & 0.57 \\
\hline A (I) & 0.55 & 0.60 & 0.48 & -0.00 & -0.09 & 0.00 \\
\hline
\end{tabular}

IC - the correlation between the individual series and the average; MS - mean sensitivity; SD - standard deviation; SNR - the signal-noise ratio; VPCP - the variability expressed through the first principal component; Rbar - the mean correlation coefficient among tree-ring series; A (I) - first-order autocorrelation. 


\section{Pointer years}

Another parameter that expresses the accuracy of climatic signals preserved in TRW is the detection of extreme years. The pointer years are mainly negative; this is a characteristic of stands affected by the aridity effect. The results indicate that the years 1918, 1946, 1974, 2002 and 2009 (Fig. 3) were extreme years. The amount of multi-annual monthly average precipitation (1901-2015) was calculated for the interval starting from the previous September to the next April and was $310 \mathrm{~mm}$. In 1918, during the same period, the amount of precipitation reached 143 $\mathrm{mm}$. The largest deficit was experienced during the January-April interval when the precipitation value (68 $\mathrm{mm}$ ) represented $46 \%$ difference from the mean multiannual average.

The year 1974 was characterized by a lower level of precipitation in January. The monthly mean precipitation was $13.3 \mathrm{~mm} / \mathrm{month}$, whereas $36.3 \mathrm{~mm} /$ month was calculated as the multi-annual average. In February, a critically low level of precipitation (8.9 $\mathrm{mm} / \mathrm{month}$ ) occurred in comparison to the $30 \mathrm{~mm} /$ month calculated for the period 1901-2015. For the other years with extremely low precipitation, the main factor driving levels of precipitation was temperature, especially in terms of the maximum values recorded in the March-May interval. Using the same selection criteria, a single positive pointer year caused by extreme precipitation was identified in all series analysed; it was 1871.

\section{Growth response to the inter-annual climate fluctuations}

Knowing tree sensitivity and climatic signal strength from the series statistics, we established a connection between the average standardized series and climatic parameters with monthly periodicity. The results emphasize that oaks of Southern Romania have a positive relationship with precipitation and a negative relationship with temperature, especially in terms of the previous growing season (Fig. 4). The relationship between precipitation and TRW is significant in January, March and May. This is common for TRW and LW, while for EW we noticed a dependence tendency towards precipitation related to the previous growing season (September). The maximum values of the correlations determined for each chronology were obtained in May (0.46 for RW and 0.51 for LW) and January (0.53 for EW).

It is important to note that the significant correlations are uneven, falsely suggesting that a tree would suspend its physiological processes from February until April (Fig. 4). When discussing the growth-precipitation correlative range, LW differs from RW only as value amplitudes, keeping the same sensitivity window.

There are two distinct characteristics of EW; the first relates to the significant correlation obtained with previous year September precipitation (0.34). The second characteristic is represented by the significant positive precipitation-growth correlation in March $(0.28)$ and by the significant negative temperature-growth correlation $(-0.36)$ in the same month.

It is noteworthy that temperature is a determinant negative factor in the bio-accumulation process in the current growing season both for EW and LW. Based on Fig. 4, monthly correlation analysis also showed significant negative relationship with temperature during April $(\mathrm{r}=-0.26)$. The most important influence on growth occurs in March $(r=-0.36)$ and is affected by EW when increasing temperatures

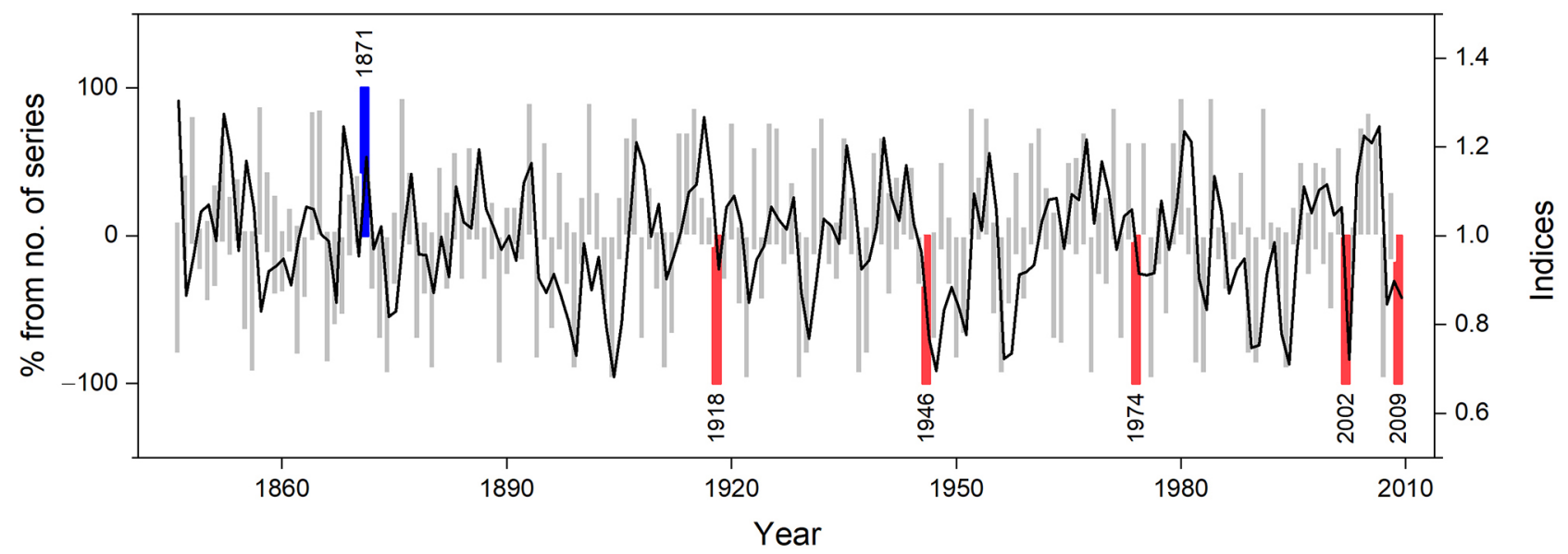

Fig. 3. Pointer years established by TRW chronology: grey bars - characteristic years found in a percentage of all series, blue bar - positive pointer extreme year, red bar - negative pointer extreme year, and solid black line - standard indices (other explanations can be found within the text) 

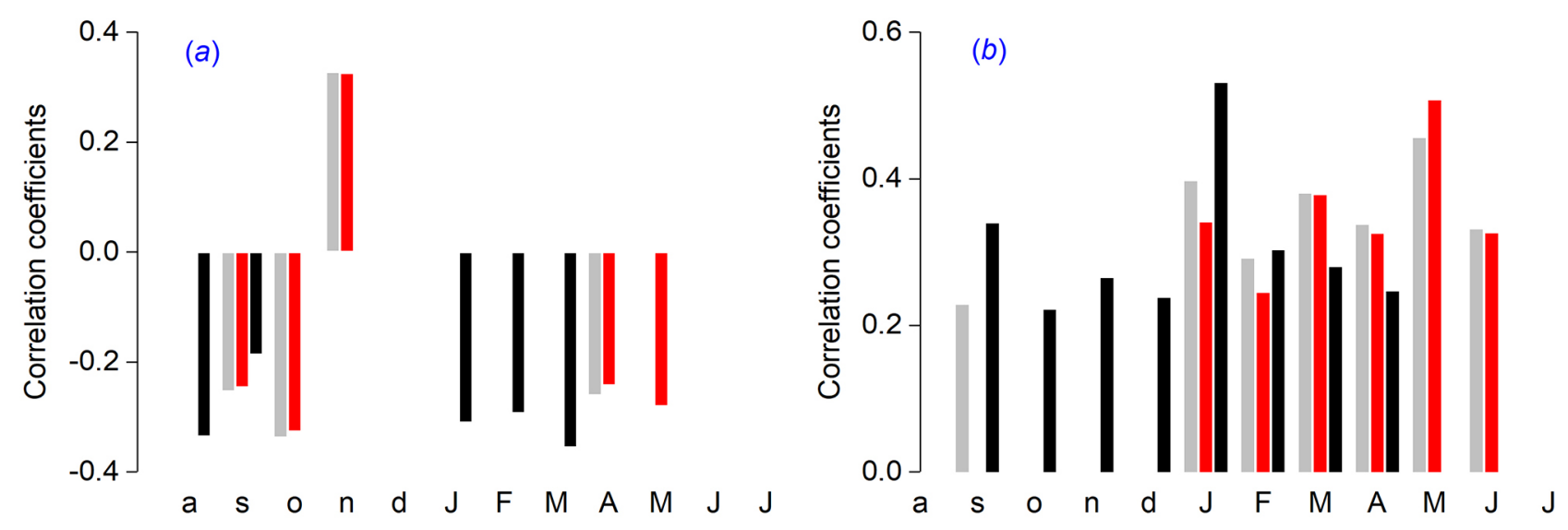

Fig. 4. Graphical representation of significant correlation coefficients between residual chronologies and climate predictors. (a) TRW (grey), LW (red), EW (black) and temperature and (b) the same chronology versus precipitation; a-d the horizontal axis represents months from the previous growing season, and $\mathrm{J}-\mathrm{J}$ represents months from the current growing season

induce more intense evapotranspiration, which causes a greater negative water balance, regardless of precipitation trends. The negative effect of temperature is much strongly manifested in EW and LW comparing with TRW.

The correlation between precipitation (as the main predictor) and radial growth on moving intervals indicates an increase in the average values for the months presented below. The January correlation for TRW reaches an average of $r=0.44$ and a maximum of $r=0.50$, registered in 1999. The correlation correspondent for May enhances this value with the multi-annual average reaching $r=0.57$, with a maximum value of $r=0.70$ in 2000 .

Based on the intra-annual measurements, we distinguished a signal amplification phenomenon, which was more evident within EW. The maximum value of the correlation, obtained in 1993, is $\mathrm{r}=0.71$, unlike LW for which the mean correlation is $r=0.58$ (maximum in $2000 \mathrm{r}=0.73$ ). The response function analysis showed a positive correlation between treering width and January of the current year and May. For EW, the value was significant only in January ( $\mathrm{r}=$ $0.27)$. This analysis indicates that $\mathrm{LW}$, in comparison to EW, responded more to precipitation in May of the current growing season $(r=0.29)$ than to any other climatic variable. According to the response function, radial growth both for EW and LW was mainly controlled by drought from the beginning of the growing season.

The results obtained using SPEI3 to estimate relationship with tree growth (Fig. 5) support the idea that the main stress factor in the study area is drought. It is also notable that there are no correlations over 0.30 for the previous year of tree-ring formation in TRW and LW. The correlations with the highest significance were recorded for EW in the September-October interval in the previous year of
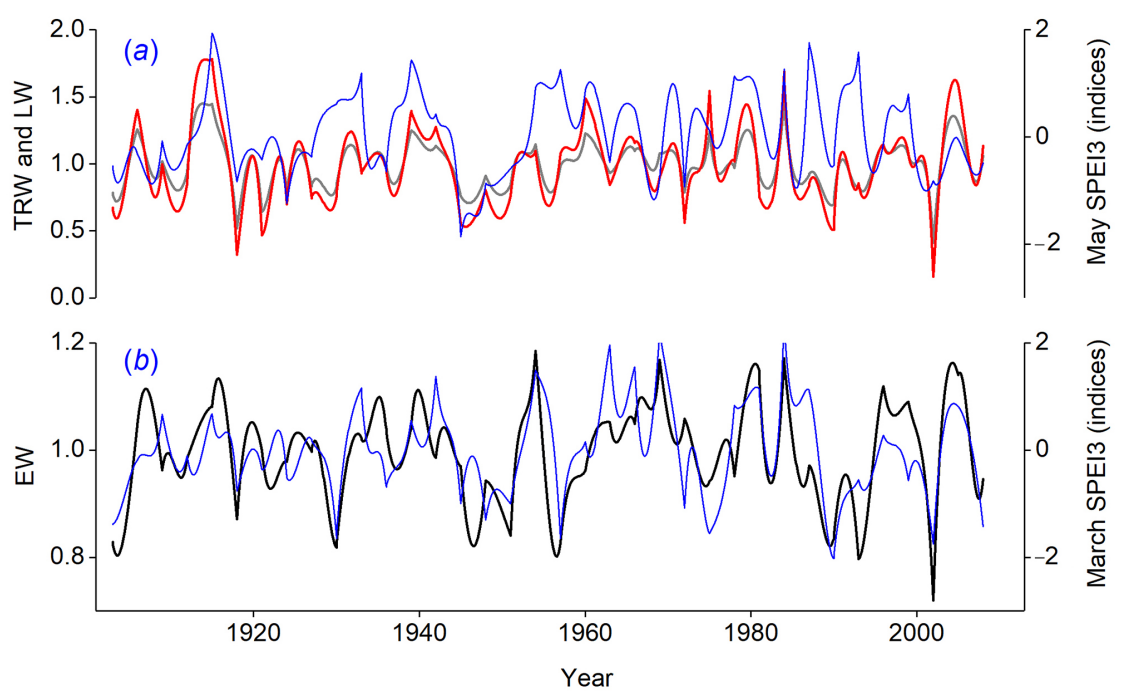

Fig. 5. The image represents (a) TRW (grey) and LW (red) versus SPEI3 May (blue) and (b) EW (black) vs. SPEI3 March (blue) 


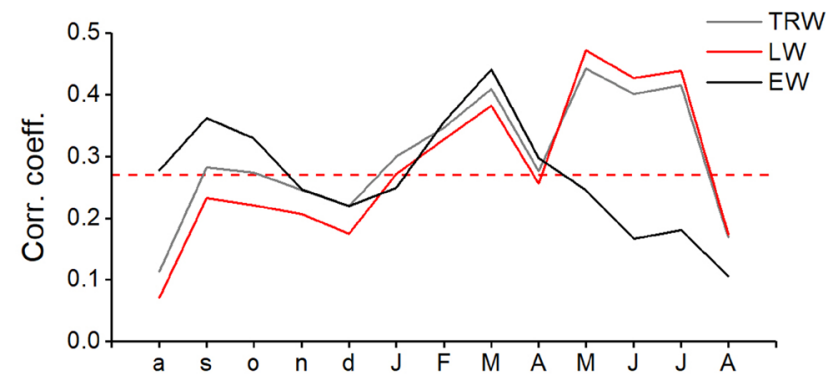

Fig. 6. Correlation coefficients between SPEI3 and TRW (grey), LW (red) and EW (black) for the period of August of the previous year to the current August. The red-dotted horizontal line represents the confidence interval limit $(95 \%)$

the growing season (0.36 and 0.33) (Fig. 6). A maximum correlation between EW and SPEI3 was obtained in March $(r=0.44)$, indicating the restrictive condition occurred for the period January-March. LW appears to be more affected by drought in comparison to TRW and EW. The maximum intensity was registered in May $(r=0.47)$.

\section{Periodic climatic registration-growth variations and sensitivity}

The potential for using oak intra-annual measurements of tree-ring series from this region in dendroclimatic studies is highlighted through the formation of a constant correlative field, with an active interval of physiological processes distinct to TRW compared to the other two wood types (EW and LW). Consequently, the first interval obtained for RW with precipitation spread over 75 days, between November 28 and February 10 and yielded a maximum correlation of $\mathrm{r}=0.42$, whereas the second interval covered the 102 days between March 4 and June 13 and yielded a maximum correlation of $\mathrm{r}=0.61$. By dividing the TRW series into EW and LW, we obtained unique significant correlative fields for each of the two wood types (Fig. 7a).

When analysing the effect of the climatic parameters separately, i.e., temperature and precipitation, using monthly and daily averages to determine the correlations, we notice the importance of EW in capturing local climate information typical for the end of the

Time span

01AUG 01SEP 01OCT 01NOV 01DEC 01Jan 01Feb 01Mar 01Apr 01May 01Jun 01Jul 01Aug 01Sep 01Oct

(days)

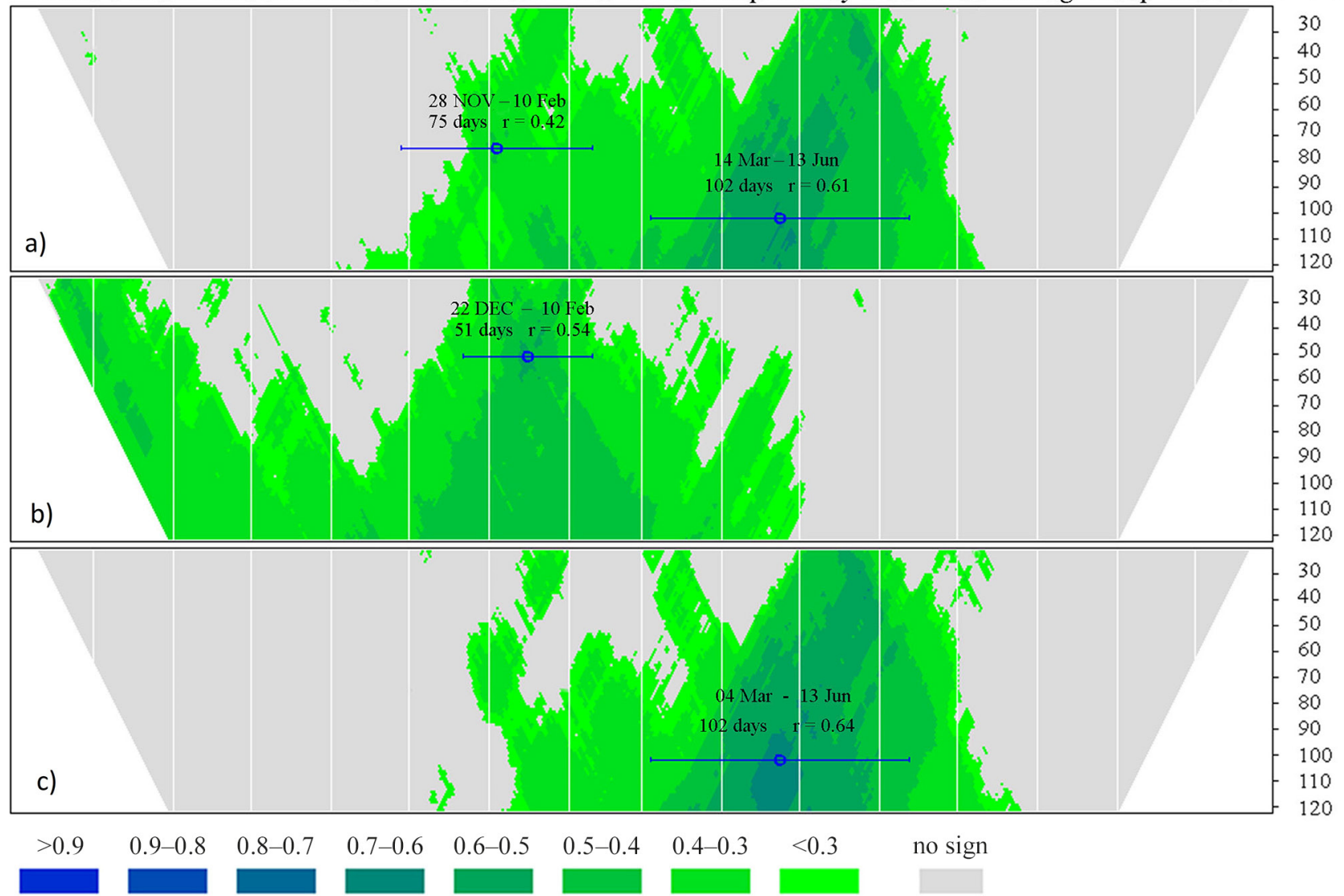

Fig. 7. Climate-growth correlation between precipitation and TRW(a), EW(b), and LW(c). The significant correlation is represented by the coloured area, beginning with August $1^{\text {st }}$ of the previous year and ending with the September $30^{\text {th }}$ of the current year 


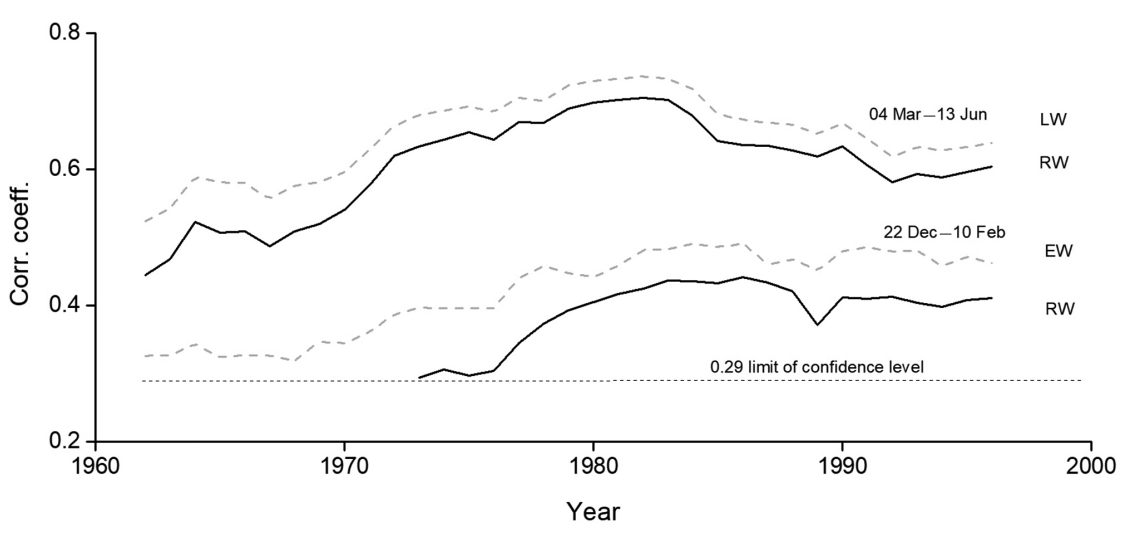

Fig. 8. Temporal stability analysis of the correlation coefficients calculated on moving averages at 24-year intervals (p-value $=0.05$ )

growing season from the previous year and for the beginning of the current growing season. For LW, it has been shown that the tree-ring is sensitive to climatic factors from the current growing season.

Thus, for EW versus average monthly temperatures, the correlations are significantly negative (August of the preceding year, January and March) and positive (November). However, when using the average daily temperature values, the high-resolution correlation analysis revealed that a tree is much more sensitive to thermal variations. In this case, four significant intervals stand out: January 14-February $13, \mathrm{r}=-0.46$; February 25-May 27, r $=-0.37$; November 16-December $6, r=0.31$; and October 3-October 23, $r=$ -0.30 . These correlations are specific to EW and are not detectable in the other wood types.

In the case of $E W$ versus average monthly precipitation corresponding to the previous growing season, the correlations are positive. The quantity of precipitation recorded in the August-September interval of the preceding year and the precipitation that falls in winter as snow, support for EW formation in the next year. Considering daily measurements, the major influence on growth is precipitation from the December 22 - February 10 interval $(r=0.54)$ and less by precipitation recorded during the preceding year (August and September) $(r=0.46)$ (Fig. 7b).

In terms of $L W$ versus the average monthly temperatures, growth is negatively affected by the minimum temperatures of May in the current vegetation year. Calculating the correlation using the daily average temperature values indicates that the 21-day time interval between May 8 and May 28 has a correlation coefficient of $\mathrm{r}=-0.34$ ).

$L W$ versus average monthly precipitation from the growing season reached the maximum correlation in May $(r=0.48)$, although significant values are also reported in January and March. By using the average daily precipitation data, the correlation increased to $r=0.64$. Another advantage of using average daily values is the capacity of estimating the period with active auxological implications between March 4 and June 13, a 102-day interval. A short period of only 23 days between June 27 and July 19 is distinguished by a significant correlation of $r=0.32$. We can assume that during this interval, physiological processes of cellular wall fortification through cellulose deposition are occurring (Fig. 7c).

$T R W$ contains almost identical information as $L W$ on the temporal stability of the correlation with the precipitation. There are small differences between the calculated average values $(r=0.65 \mathrm{LW}$ and $r=0.60 \mathrm{RW})$. The minimum values range over a larger interval, between $r=0.52(\mathrm{LW})$ and $\mathrm{r}=0.45(\mathrm{RW})$. However, the maximum values of the correlation computed for the two wood types are $r=0.74(\mathrm{LW})$ and $\mathrm{r}=0.71$ (TRW)).

To successfully model a climatic reconstruction based on radial growth tree-rings, a major factor is the temporal stability analysis of the calculated correlation with the climatic parameter (Fig. 8). In this case, we noted several implications, which support the importance of studying an annual tree-ring by its components (EW and LW). First, we observed a very significant change in correlation strength between RW and LW in May 04- June 13 in the 1960s ( $r=$ 0.52 for LW and $r=0.44$ for RW), which then increased until $r=0.73(\mathrm{LW})$ and $\mathrm{r}=0.70(\mathrm{RW})$ in the 1980s, and the r-value decreased again to $r=0.60$ (LW) and $r=0.60$ (RW) in the 1990s. In terms of $\mathrm{EW}$, the period prior to the current growing season, December 22-February 10 is when the correlation was stable and increased from almost $r=0.30$ in the 1960 s to $r=0.49$ in the 1980s and decreased to $r=$ 0.46 in the 1990s.

Within TRW, the start of the vegetation season is not that visible during the first part of the studied interval. However, by increasing the resolution of an annual tree-ring study, the correlation between precipitation and EW becomes stable over time.

When analysed individually, EW extends its correlative field over the ending months of the preceding 

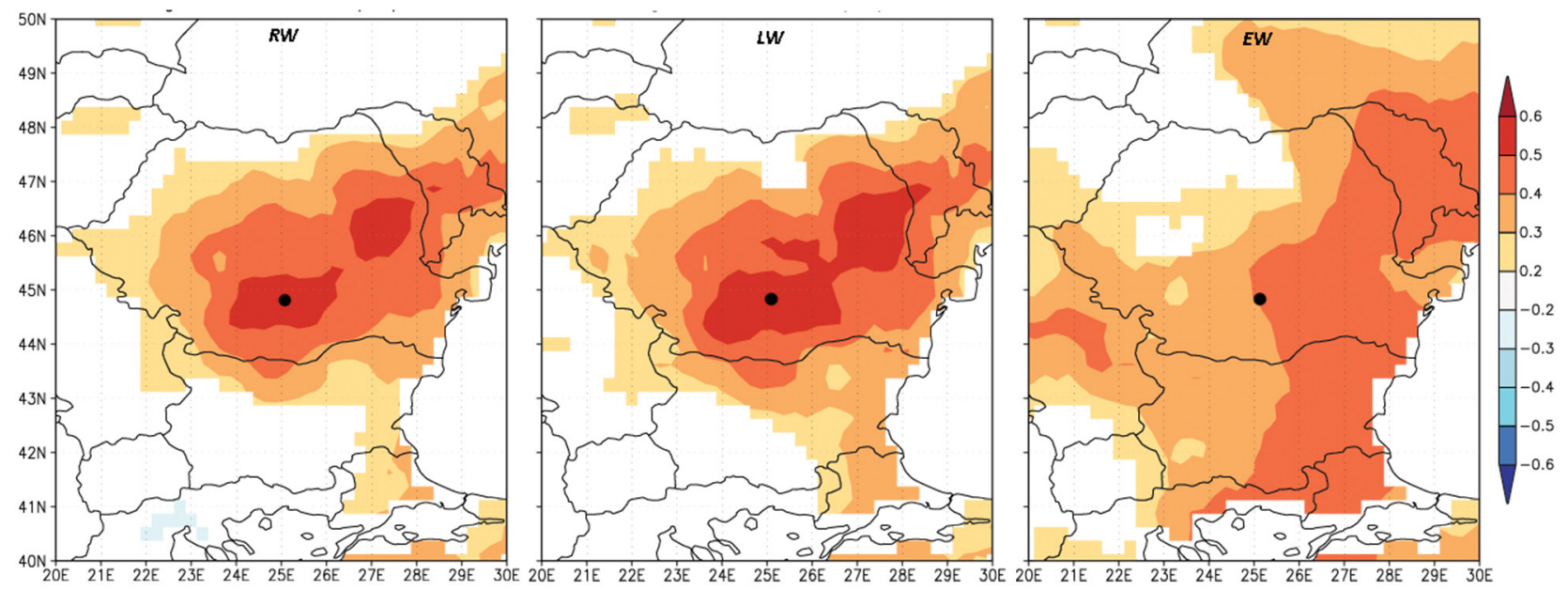

Fig. 9. Spatial depiction of the correlation between oak tree-ring indices (residual chronology) and gridded CRU TS 3.1 July (TRW and LW) and March (EW) precipitation (significance level is 95\%) for 1901-2009 (Trouet \& Oldenborgh, 2013)

year's growing season; the active physiological period decreases to 51 days; and the correlation level decreases non-significantly compared to the one calculated by using TRW indices, which is also valid for the LW. The correlations maintain stability even though the min-max span reaches 0.26 , such as the case of TRW during March 4-June 13.

\section{Spatial correlations}

Using the residual chronology for oak trees from southern Romania and the correlation with July precipitation (TRW and LW) and March precipitation (EW), respectively, we obtained the regional distribution of the climatic signal based on the oak tree (Fig. 9).

The spatial correlation field shows an overlay in southern and eastern Romania for all three tree-ring parameters. The TRW and LW records are almost identical, with maximum correlations in the study area and a concentric disposition and residual for eastern Romania. For the EW series, the correlation presents an extension towards East Bulgaria and the East European Plain, towards the North of the Black Sea.

\section{Discussions}

A mean value of the radial growth of $1.88 \mathrm{~mm} /$ year (ranging between $0.93 \mathrm{~mm} /$ year and $3.08 \mathrm{~mm}$ / year) was determined by Friedrichs et al. (2008) for Central Europe. Local studies within Romania (Nechita, 2013) show an average radial growth of 2.23 $\mathrm{mm}$ /year (ranging from $1.24 \mathrm{~mm} /$ year to $3.6 \mathrm{~mm}$ / year). The extreme values are recorded in northern Romania (Maramureș, minimum values) and in the east (Moldova Plateau, maximum values) (Nechita et al., 2017). The Mănăstioara site on the Romanian Plain would fit into the median portion of this variation range.

The analysis of the statistical parameters of the dendrochronological series highlights the fact that the investigated series have different characteristics compared to those in Central Europe; these series exhibit spatial variation even across Romania. Climatic information representative of the current year's tree-ring formation is preserved in LW. The climatic signal recorded during the last months of the growing season in the year that precedes the formation of the tree-ring resides in EW (Garcia-González \& Eckstein, 2003).

The main objective of our study was to interpret regional climate fluctuations by investigating the correlation between growth rings and restrictive climatic factors. This process was based on the physiologic analysis of trees, by reinterpreting the correlation coefficients after replacing the monthly values of the climatic parameters with the daily value. The results provided us information on the physiological behaviour of the oak tree, knowing that energy exchange with the environment is a continuous process.

A correlation that includes climatic parameters as monthly averages cannot provide a complete result. This study suggests that the use of daily records of climatic parameters improves our knowledge on the climatic signals preserved and reflected in the physiological behaviour of the oak tree.

The data presented in Fig. 5 is suggestive of this point of view and emphasizes the importance of EW in the interpretation of the local climatic variations. It is noteworthy that most studies (Garcia-González \& Eckstein, 2003; Tardif \& Conciatori, 2006; Sohar et al., 2013; Kern et al., 2013) emphasize the importance of LW, disregarding the potential of EW. Our results reveal that differentiating the analysis of 
radial growth into EW and LW is an effective way of determining and understanding climatic impacts on oak tree growth in southern Romania, as discussed in previous studies (Rădoane et al., 2015).

The statistical variables indicate high values of the inter-annual coherence of radial growth at the stand level associated with the residual series (RES) after standardization due to the maximization of the residual information and the removal of noise. The statistics of the chronology encompass efficiency values that reflect the sensitivity of the trees in the study area to climate changes. The first-order autocorrelation supports the theory that the effect of the previous year's climate on tree growth is more intense in EW compared to the TRW and LW series (Garcia-González \& Eckstein, 2003; Matisons et al., 2013).

The comparison of these results with other oak tree series developed in Romania (Nechita, 2013) shows that the values are similar to the sessile oak series from the same site and that higher values were recorded in the centre of the Romanian Plain, where the average sensitivity for the latewood is $62 \%$. The highest value, $71.25 \%$, was calculated for the Mătăsaru oak tree dendrochronological series (at approximately $20 \mathrm{~km}$ from the study site) and is a good value for Romania. The average sensitivity interval of the Quercus family trees is from $5 \%$ to $72 \%$ (Pilcher \& Gray, 1982; Rozas, 2001; Lebourgeois et al., 2004).

The positive correlation between EW and temperatures from the previous year shows that a warm November is beneficial for physiological processes. The cold continental fronts induce significant negative effects on growth during January and March in the study area. In January, the correlation between annual tree-ring width and temperature $(r=-0.34)$ is opposite to the annual tree-ring-precipitation correlation $(r=0.41)$. Earlywood indicate difficult conditions during the spring growth (Battipaglia et al., 2010). Oak trees located in warm, low elevation sites may dispose winter and early spring moisture most efficiently, higher temperature in winter might induce an earlier start of the growing season.

The results show that the $Q$. robur growth in the southern Romania is mainly, but not exclusively, conditioned by precipitation. Temperature from the previous season positively influences tree-ring formation, and negative temperatures from the current growth year also play an important role in growth. Using SPEI3, we demonstrated that the growth of oak tree depends on aridity and evapotranspiration. Our results are comparable to studies in central-western Germany, where oak trees respond to the previous year's precipitation regime until the end of the current growing season, with a maximum during the March-May interval (Friedrichs et al., 2008).

The regional distribution of the oak tree EW correlations supports that the East European region has a temperate climate with continental influences. Based on Cufar et al. (2008b) who state that "oak growth in Europe is driven and controlled by a common factor - climate" (page 132), we support that climatic information is stored both in EW and LW.

The heteroconnections of oak tree spatial correlations compared to Pinus nigra correlations (Levanič et al., 2013) demonstrate the climate prediction capacity of various tree species. For the latter, spatial correlations indicate an area of the southwestern area of Romania, which extends towards a climatic region with Mediterranean influences, from northwestern Bulgaria and eastern Serbia. A recent re-evaluation of the cited Pinus nigra records showed that it can be interpreted as a mixed signal of drought and an early spring temperature, especially in the high-frequency signal (Kern et al., 2016).

The study area corresponds to the Pinus nigra ecosystem within this part of Europe, as we highlighted the area of the Quercus robur ecosystem for southeastern Europe. Although both species respond to precipitation, the spatial coverage of the correlation of precipitation with climate does not overlay, and for this reason, we focused on a series for the oak tree species, which could then be applied in climate reconstruction.

The results obtained by quantifying the climate-radial growth relationship indicate that growth depends on precipitation. Temperature acts contrary to precipitation during the months with significant and positive values of precipitation-growth correlations, while negative significant temperature-growth correlations are also obtained. The significant correlations calculated for the mean growth transformed into residual indices and the standardized precipitations index (SPEI3) demonstrated that the oak trees in the study area are affected by drought.

Normally, temperature is not a source of stress in low-elevation areas, where precipitation is the main restrictive factor. However, if during the growing season, temperatures increase above the limit tolerated by the species, then this increase in temperature would have a negative influence on growth by increasing the evapotranspiration. The significant correlations obtained for temperature in September, October and November $(t-l)$ and in August and September for precipitation were also found in other studies that studied oak trees (Pilcher \& Gray, 1982; Lebourgeois et al., 2004; Nechita, 2013). This positive response can be explained physiologically by the influence of the amount of snow accumulated in the winter and released during the spring, which can result in an early start of the growing season.

Finally, the results regarding growth response to annual and intra-annual climatic fluctuations show different behavior for each of the three wood types (RW, EW and LW). All wood types exhibit an increased sensitivity (positive correlation) to 
precipitation, but the significance of the correlations is not the same for certain months of the year; only EW and LW respond negatively to the temperature factor. TRW does not exhibit these negative influences as being significant in the current season of tree-ring formation. Consequently, to determine the continuity of the tree-growth physiological formation process, we considered it necessary to remove the temporal barrier imposed by monthly average climatic data, and we considered average daily climate data, calculated over time intervals.

\section{Conclusions}

The stress factor resulting from the lack of precipitation represents a limiting factor for oak tree growth in southern Romania. By separating the analysis for EW and LW, we clearly differentiate EW dependence on the conditions from the previous year and from January and March. LW, which is strictly conditioned by precipitation from the current year, points to a maximum correlation in May, which is associated with the most intense biomass accumulation period for trees in hills and plains areas. The results reveal the high potential of the series to serve as material for further studies on different scenarios that can affect the future of oak trees within the study area, in the context of climate change.

\section{Acknowledgements}

Above all, we would like to present our thankfulness, with utmost sincerity, to the anonymous reviewers for their consistent advice and remarks. This work was supported by a grant from the Romanian National Authority for Scientific Research and Innovation, CNCS-UEFISCDI, project number PN-II-RUTE-2014-4-0855 "Reconstruction of Late Holocene History of Romanian rivers based on geomorphological and dendrochronological interpretation of subfossil trunks" (RECONHIST, FC). This work was also, supported by a grant from the Romanian National Authority for Scientific Research and Innovation, CNCS/ CCCDI-UEFISCDI, project number PN-III-P2-2.1PED-2016-1058, within PNCDI III "A new technique regarding dendrochronological dating. Statistical, biological and chemical approach" (DendroTECH, CN).

\section{References}

Battipaglia G, De Micco V, Brand WA, Linke P, Aronne G, Saurer M \& Cherubini P (2010) Variations of vessel diameter and $\delta^{13} \mathrm{C}$ in false rings of Arbutus unedo L. reflect different environmental conditions. New Phytologist 188: 1099-1112.
Beck W, Sanders T \& Pofahl U (2013) CLIMTREG: detecting temporal changes in climate growth reactions - a computer program using intra-annual daily and yearly moving time intervals of variable width. Dendrochronologia 31: 232-241.

Becker M, Nieminen TM \& Gérémia F (1994) Shortterm variations and long-term changes in oak productivity in northeastern France. The role of climate and atmospheric $\mathrm{CO}_{2}$. Annals of Forest Science 51: 477-492.

Biondi F \& Waikul K (2004) DENDROCLIM 2002: A $\mathrm{C}++$ program for statistical calibration of climate signals in tree-ring chronologies. Computers \& Geosciences 30: 303-311.

Briffa K \& Jones PD (1990) Basic chronology statistics and assessment: Methods of Dendrochronology: Applications in the Environmental Sciences (ed. by ER Cook \& LA Kairiukstis) Kluwer Academic Publishers, Dordrecht, Netherlands, pp. 137-152.

Buras A (2017) A comment on the expressed population signal. Dendrochronologia 44: 130-132.

Cook ER \& Holmes RL (1986) Users manual for program ARSTAN. Laboratory of Tree-Ring Research. University of Arizona, Tucson, USA.

Cook ER, Briffa KR, Shiyatov S, Mazepa V \& Jones PD (1990) Data analysis: Methods of dendrochronology: applications in the environmental sciences (ed. By ER Cook \& LA Kairiukstis) Kluwer Academic Publishers, Dordrecht, Netherlands, pp. 97-162.

Cooper RJ, Melvin TM, Tyers I, Wilson RJS \& Briffa KR (2013) A tree-ring reconstruction of East Anglian hydroclimate variability over the last millennium. Climate Dynamics 40: 1019-1039. doi:10.1007/s00382-01201328-x.

Cropper JP (1979) Tree-ring skeleton plotting by computer. Tree Ring Bulletin 39: 47-60.

Čufar K, de Luis M, Eckstein D \& Kajfez-Bogataj L (2008a) Reconstructing dry and wet summers in SE Slovenia from oak tree-ring series. International Journal of Biometeorology 52: 607-615. doi:10.1007/s00484-008-0153-8.

Čufar K, de Luis M, Eckstein D \& Kajfez-Bogataj L (2008b) A 548-years long tree-ring chronology of oak (Quercus spp.) for SE Slovenia and its significance as dating tool and climate archive. Tree Ring Research 64: 3-15.

Čufar K, Grabner M, Morgós A, Martínez del Castillo E, Merela M \& de Luis M (2014) Common climatic signals affecting oak tree-ring growth in SE Central Europe. Trees 28: 1267-1277. doi:10.1007/s00468-013-0972-z.

Dobrovolný P, Rybníček M, Koláŕ T, Brázdil R, Trnka M \& Büntgen U (2015) A tree-ring perspective on temporal changes in the frequency and intensity of hydroclimatic extremes in the territory 
of the Czech Republic since 761 AD. Climate of the Past 11: 1453-1466. doi:org/10.5194/cp-111453-2015.

Dumitrescu A \& Birsan MV (2015) ROCADA: a gridded daily climatic dataset over Romania (19612013) for nine meteorological variables. Natural Hazards 78: 1045-1063.

Fonti P, von Arx G, Garcia-González I, Eilmann B, Sass-Klaassen U, Gärtner H \& Eckstein D (2010) Studying global change through investigation of the plastic responses of xylem anatomy in tree rings. New Phytologist 185: 4253.

Friedrichs D, Büntgen U, Frank D, Esper J, Neuwirth B \& Löffler J (2008) Complex climate controls on the 20th century oak growth in Central-West Germany. Tree Physiology 29: 39-51.

Fritts HC (1976) Tree rings and climate. Academic Press Ltd., London, Great Britain.

Garcia-González IG \& Eckstein D (2003) Climatic signal of earlywood vessels of oak on a maritime site. Tree Physiology 23: 497-504.

García-Suárez AM, Butler CJ \& Baillie MGL (2009) Climate signal in tree-ring chronologies in a temperate climate: a multi-species approach. Dendrochronologia 27: 183-198. doi:10.1016/j.den dro.2009.05.003.

Gentilesca T, Camarero JJ, Colangelo M, Nolè A \& Ripullone F (2017) Drought induced oak decline in the western Mediterranean region: an overview on current evidences, mechanisms and management options to improve forest resilience. iForest 10: 796-806. doi:10.3832/ifor2317-010.

Haneca K, Čufar K \& Beeckman H (2009) Oaks, treerings and wooden cultural heritage: a review of the main characteristics and applications of oak dendrochronology in Europe. Journal of Archaeological Science 36: 1-11.

Harris I, Jones PD, Osborn TJ \& Lister DH (2014) Updated high-resolution grids of monthly climatic observations - the CRU TS3.10 Dataset. International Journal of Climatology 34: 623-642, doi:10.1002/joc.3711.

Holmes RL (1983) Computer-assisted quality control in tree-ring dating and measurement. Tree Rings Bulletin 43: 69-78.

Kern Z, Németh A, Gulyás MH, Popa I, Levanič T \& Hatvani IG (2016) Natural proxy records of temperature and hydroclimate variability with annual resolution from the Northern Balkan-Carpathian region for the past millennium - Review \& recalibration. Quaternary International 45: 109-125.

Kern Z, Patkó M, Kázmér M, Fekete J, Kele S \& Pályi $\mathrm{Z}$ (2013) Multiple tree-ring proxies (earlywood width, latewood width and ${ }^{13} \mathrm{C}$ ) from pedunculate oak (Quercus robur L.), Hungary. Quaternary International 293: 257-267.
Koláŕ T, Kyncl T \& Rybníček M (2012) Oak chronology development in the Czech Republic and its teleconnection on a European scale. Dendrochronologia 30: 243-248. doi:10.1016/j.dendro. 2012.02.002.

Lebourgeois F, Cousseau G \& Ducos Y (2004) Climate-tree-growth relationships of Quercus petraea Mill. stand in the Forest of Bercé ("Futaie des Clos", Sarthe, France). Annals of Forest Science 61: 361-372.

Levanič T, Popa I, Polajanšek S \& Nechita C (2013) A 323-year long reconstruction of drought for SW Romania based on black pine (Pinus Nigra) treering widths. International Journal of Biometeorology 57: 703-714.

Maaten-Theunissen van der M \& Bouriaud O (2012) Climate-growth relationships at different stem heights in silver fir and Norway spruce. Canadian Journal of Forest Research 42: 958-969.

Matisons R, Elferts D \& Brūmelis G (2013) Possible signs of growth decline of pedunculate oak in Latvia during 1980-2009 in tree-ring width and vessel size. Baltic Forestry 19(1): 137-142.

McKee TB, Doesken NJ \& Kleist J (1993) The relationship of drought frequency and duration to time scales. Preprints, Eighth Conference on Applied Climatology, January 17-22, Anaheim, California, pp. 179-184.

Nechita C, Popa I \& Eggertsson O (2017) Climate response of oak (Quercus spp.), an evidence of a bioclimatic boundary induced by the Carpathians. Science of the Total Environment 599-600: 1598-1607.

Nechita C (2013) Rețeaua națională de serii dendrocronologice pentru stejar și gorun. Editura Silvică, București, Romania.

Pilcher JR \& Gray B (1982) The relationship between oak tree growth and climate in Britain. Journal of Ecology 70: 297-304.

Pritzkow C, Wazny T, Heußner KU, Słowiński M, Bieber A, Liñán ID, Helle G \& Heinrich I (2016) Minimum winter temperature reconstruction from average earlywood vessel area of European oak (Quercus robur) in N-Poland. Palaeogeography. Palaeoclimatology. Palaeoecology 449: 520-530.

Rădoane M, Nechita C, Chiriloaei F, Rădoane N, Popa I, Roibu C \& Robu D (2015) Late Holocene fluvial activity and correlations with dendrochronology of subfossil trunks: Case studies of northeastern Romania. Geomorphology 239: 142-159.

Rinn F (1996) TSAP. Time series analysis and presentation. Version 3.0 reference manual. Heidelberg, Germany.

Rozas V (2001) Detecting the impact of climate and disturbances on tree - rings of Fagus sylvatica L. and Quercus robur L. in a lowland forest in Can- 
tabria, Northern Spain. Annals of Forest Science 58: $237-251$.

Sohar K, Helama S, Läänelaid A, Raisio J \& Tuomenvirta $\mathrm{H}$ (2013) Oak decline in a southern Finish forest as affected by a drought sequence. Geochronometria 41: 92-103.

Stajić B, Vučković M \& Janjatović Ž (2015) Preliminary dendroclimatological analysis of Sessile oak (Quercus petraea (Matt.) Liebl.) in "Fruška Gora" National Park, Serbia. Baltic Forestry 21: 83-95.

Tardif JC \& Conciatori F (2006) Influence of climate on tree rings in red oak and white oak growing near their northern distribution limit, southwestern Quebec, Canada. Canadian Journal of Forest Research 36: 2317-2330. doi:10.1139/x06-133.

Trnka M, Brázdil R, Možný M, Štěpánek P, Dobrovolný $\mathrm{P}$, Zahradníček $\mathrm{P}$, Balek J, Semerádová $\mathrm{D}$, Dubrovský M, Hlavinka P, Eitzinger J, Wardlow B, Svoboda M, Hayes M \& Žalud Z (2015) Soil moisture trends in the Czech Republic between 1961 and 2012. International Journal of Climatology 35: 3733-3747.

Trouet V \& Van Oldenborgh GJ (2013) KNMI Climate Explorer: a web-based research tool for high-resolution paleoclimatology. Tree-Ring Research 69: 3-13.

Ważny T, Lorentzen B, Köse N, Akkemik Ü, Boltryk Y, Güner T, Kyncl J, Kyncl T, Nechita C, Sagaydak S \& Kamenova Vasileva J (2014) Bridging the gaps in tree-ring records: creating a high-resolution dendrochronological network for southeastern Europe. Radiocarbon 56: S39-S50 and Tree-Ring Research 70: 39-50.

Wigley TML, Briffa KR \& Jones PD (1984) On the average value of correlated time-series, with applications in dendroclimatology and hydrometeorology. Journal of Climate and Applied Meteorology 23: 201-213. 